\title{
THE REDISTRIBUTIVE IMPACT OF ALTERNATIVE INCOME MAINTENANCE SCHEMES: A MICROSIMULATION STUDY USING SWISS DATA
}

\author{
By Ramses H. Abul Naga \\ Department of Economics and International Development, University of Bath \\ Christophe KolodziejCZyK \\ AKF Danish Institute of Governmental Research, Copenhagen \\ AND \\ TOBIAS MÜLLER* \\ Department of Econometrics, University of Geneva
}

Taking a benchmark scenario, the current situation in Switzerland, and using a microsimulation technique, we compare the effectiveness of various income maintenance schemes for reducing inequality and poverty. A full negative income tax allowance designed to eliminate poverty is shown to reduce income inequality most drastically. An integrated federal linear tax rate of 62 percent is required to make it viable. Aggregate work hours are reduced by approximately 10 percent and average disposable income falls by 9.3 percent under such circumstances. A participation income restricted to adults in employment and covering 50 percent of subsistence costs is however shown to result in an unambiguous social welfare improvement over the current situation in Switzerland.

\section{INTRODUCTION}

Undoubtedly, one of the principal goals of the welfare state is to provide a social safety net for families whose incomes are likely to fall below a critical threshold, and more generally to redistribute resources in an equitable manner. Because social insurance schemes are often funded from income taxation, the government must always trade off these justice objectives against the distortions caused by taxation, especially when these result in significant reductions of work hours of individuals with a capacity to generate high earnings.

Alternative income maintenance schemes generate different budget constraints for households, and, in theory at least, different labor supply responses. For this reason, they will not be equally effective at reducing poverty and inequality; likewise they will not be equally costly in terms of tax revenue requirements. Hence, alternative income maintenance schemes may be taken to imply qualitatively different trade-offs between equality and efficiency. The purpose of this

Note: We are grateful to two anonymous referees for their very helpful comments and suggestions on a previous version of this paper. This research was funded by grant no. 4045-59741 from the Swiss National Science Foundation ("Future Problems of the Welfare State" program).

*Correspondence to: Tobias Müller, Department of Econometrics, University of Geneva, 40 boul. du Pont-d'Arve, 1211 Geneva 4, Switzerland (Tobias.Mueller@metri.unige.ch).

(C) 2008 The Authors

Journal compilation (C) 2008 International Association for Research in Income and Wealth Published by Blackwell Publishing, 9600 Garsington Road, Oxford OX4 2DQ, UK and 350 Main St, Malden, MA, 02148, USA. 
study is precisely to study the effect of various income maintenance schemes on poverty, inequality and social welfare. Summary statistics for the underlying level of poverty and inequality are computed. However, because the question we ask is essentially a qualitative one, we also undertake an ordinal analysis of the income distributions pertaining to the various policy scenarios, examining the underlying Lorenz and poverty deficit curves. The social welfare criterion embodies a preference for higher incomes, and accordingly provides a means of comparing alternative policy scenarios which generate different levels of aggregate income. Thus, income distributions pertaining to key scenarios of interest are also compared in the light of the generalized Lorenz criterion.

Taking a benchmark scenario, the current distribution of household disposable income in Switzerland for individuals in paid employment, or seeking employment and available for work, we are also interested in examining if any of the policy scenarios we examine can result in a social welfare improvement over the reference situation. ${ }^{1}$ The various schemes examined here include a full negative income tax allowance, a partial negative income tax allowance, a participation income covering 50 percent of the subsistence cost of living, an income support scheme which tops up household resources to the level of subsistence expenditure, and a simplified form of an earned income tax credit.

As stated above, alternative income support schemes result in different budget constraints for households. In this sense, it would be somewhat arbitrary to assume that household labor supply remains fixed across policy scenarios. For this reason, our chosen method of investigation is to undertake a microsimulation study of family labor supply responses, comprising an estimated econometric model coupled with an integrated tax-benefit module that models the budget constraint of every household under different policy scenarios. The microsimulation method has been used to investigate the incentive effects of welfare reform packages such as the Earned Income Tax Credit in the U.S., and the Working Families Tax Credit in the U.K. (see Blundell and MaCurdy, 1999 as well as Blundell, 2001 for discussions). A similar study in the Swiss context is that of Gerfin and Leu (2003), where the authors propose to examine, by means of a microsimulation technique, the likely effects on poverty and labor force participation of the introduction of an earned income tax credit.

It is important to note however that studies of this type (e.g. Duncan and Giles, 1996, 1998) pay cursory attention to the overall distributional impact of tax credit reforms, choosing to focus instead on labor supply responses (because such schemes are primarily intended to stimulate participation). Our paper thus departs from this literature by placing the emphasis of the analysis on changes in the income distribution.

Social security reform has been high on the agenda of most developed countries. The American Earned Income Tax Credit (EITC), and the British Working Families Tax Credit (WFTC), have been the subject of various evaluation studies (see Blundell and MaCurdy, 1999 for a survey). The rationale underlying these programs is to induce increased participation of low income workers in the labor

\footnotetext{
${ }^{1}$ The self-employed are excluded from our analysis primarily because of poor data quality. See the data appendix of Abul Naga et al. (2007) for further details.
} 
force. The Negative Income Tax (NIT) and Basic Income (BI), two related income support schemes, are more predominantly intended to redistribute resources to the poor population, independently of their work decisions.

The proposal for a NIT first appeared in Milton Friedman's Capitalism and Freedom. Though it was never implemented, it has also shaped a great deal of recent U.S. welfare policy as argued, for instance, by Moffitt (2003). Friedman (1962) intended to substitute the NIT for the "rag bag" of multiple welfare programs. This was argued to save administrative costs, and was also argued to be beneficial on the grounds that the NIT would "integrate" the tax system. The NIT would not intrude into people's privacy since other than a means test, welfare officers were not required to evaluate individuals' capacity to work, how hard they have tried to find work, etc. Because of the universal nature of this policy package, the NIT was also argued to reduce welfare stigma (an analysis of which is presented in Moffitt, 1983) and not to interfere with marriage decisions and family composition.

The Basic Income and accompanying flat tax proposal is extensively discussed in Atkinson (1995). The basic income proposal shares many features with the NIT. Under the BI proposal the tax rate on all income sources is intended to be identical, obviating the need to define a tax unit. Thus, unlike in the NIT, the benefit recipient in the case of the $\mathrm{BI}$ is the individual and not the family. The tax rate on income is intended to be flat, in order to save on the administrative costs of operating a graduated tax schedule. The linear income tax rate envisaged is perhaps in the order of 0.4 to 0.5 .

We devote a large part of our study to the examination of the effect on income distribution of the introduction of a combined negative income tax allowance and a flat tax. The related basic income and flat tax proposal has been the focus of the study of Atkinson (1995). Our study is similar in emphasis to that of Creedy and Dawkins (2002), which addresses several issues raised in Atkinson (1995) by comparing the working of a means tested benefit versus a universal coverage. Creedy and Dawkins use a simulation method to address their concerns, whereas this study is based on a micro-simulation technique with reference to Swiss household data. As is most often the case, the particularities and level of realism underlying a microsimulation model (MSM) are chosen to reflect the nature of the question one wishes to address. At one end, one finds arithmetic MSMS designed primarily to study the impact of marginal reforms on household welfare (see Bourguignon and Spadaro, 2006 for a discussion) which abstract from behavioral responses in the aftermath of policy reforms. At the other end we find the level of generality proposed by Fredriksen and Stølen (2007) and Merz (1996), where events such as changes in family composition, the decision to migrate, or mortality risk ${ }^{2}$ are taken into account.

We are primarily interested in labor supply reactions of households in the face of alternative tax and benefit schemes. Thus, we follow Orsini (2006) and Steiner and Wrolich (2006) in adopting the discrete choice hours of work framework initially proposed by van Soest (1995) for modeling behavioral responses. It is to be noted that labor demand is assumed infinitely elastic in this approach. Because

${ }^{2}$ See in particular the description of the Mosart MSM the authors of the study provide. 
the tax reforms we study have to be judged in relation to their distributional impact but also in relation to their feasibility, it is important that the various policy reforms we examine be comparable in terms of the costs they entail. For this reason we have chosen to implement the various programs under the requirement of fiscal neutrality, as in Aaberge et al. (2004).

It is plausible in practice that given two households with identical characteristics and occupational choices, they respond differently to a change in the tax/ benefit system which concerns them equally. This is the problem of unobserved heterogeneity in relation to labor supply responses (see Bourguignon and Spadaro, 2006). To accommodate this source of unobserved heterogeneity, we simulate (as in Gerfin and Leu, 2003) a pseudo-residual for each household, chosen so as to make the predicted occupational choice of the household conform with its utility maximizing choice under the benchmark scenario.

Perhaps one feature of our study which sets it apart from the papers mentioned above, is our emphasis on the ordinal analysis of the effect of policy reform on income distribution. Again, our interest in poverty and inequality reduction and not in changes in work hours per se, has geared our analysis toward these normative aspects of policy reform.

In this sense, it is hoped that the present study presents a step in the direction of adding realism to the evaluation of the redistributive impact of various income maintenance schemes.

Section 2 of the paper presents the policy scenarios which form the basis of our study. Results are presented in Sections 3 and 4. Section 5 contains a detailed examination of the unique policy scenario which entails a general welfare improvement over the current situation in Switzerland. Section 6 concludes the paper. A technical appendix containing the details of our policy evaluation methods and a data appendix presenting the sample used in the study are available in Abul Naga et al. (2007).

\section{Policy Scenarios}

The tax reform scenarios we have chosen to simulate are intended to capture some features of the different schemes discussed above, and of the current situation in Switzerland. However because of the fiscal federalism in Switzerland, they are considerably simplified in order to be easily implemented in the context of our study. All in all we have considered eight scenarios, a benchmark scenario, which we have termed base in Table 1, together with six other schemes. We begin with a summary of the general structure of the Swiss tax and benefit system.

Income taxes are levied at three different levels in Switzerland: federal, cantonal and municipal. There are different tax schedules that operate for each canton and there is also a distinct federal income tax schedule. In general, each canton chooses to operate a separate schedule for each of the main two demographic groups: singles and married couples. This is also the case with regard to the federal income tax. Municipal taxes are set as a proportion of cantonal taxes. Note that the cantonal tax schedules vary a great deal in terms of progressivity. Every canton will also allow for some tax deductions, in relation to the number of dependent 
children and also in relation to social insurance and pension fund contributions. Again these tax deduction rules are fairly heterogeneous across cantons.

Social insurance contributions operate at both the federal and cantonal level. Two major federal level payroll deductions are unemployment insurance (approximately 1 percent of gross earnings) and old age insurance (AVS) - the first tier of pension contributions amounting to about 5.25 percent of gross earnings. The second tier of the retirement pension scheme is operated by private pension funds subject to a legal minimum levying rate. Similarly, social benefits are administered by both federal and cantonal authorities. Unemployment benefits are determined at the federal level. Individuals who have contributed for a six month period are entitled to 70-80 percent of their gross earnings over a 24 month period. The take-up of a basic health insurance scheme is compulsory. Government regulated private insurance providers insure individuals. The actual insurance premiums are not determined by the individual's income or wealth, but rather according to their age group. Cantons however provide rebates to households with limited means. Health insurance rebates as well as housing and child benefits are administered by the cantons. The rules as to who qualifies for these cantonal benefits, the means test, and the level of the transfer are all subject to the canton's discretion.

However, the guidelines of the Swiss Conference on Social Support (CSIAS, 2000) regarding the minimum subsistence income are generally followed by the relevant cantonal authorities. For this same reason, in applied work on Switzerland, the equivalence scale and related income thresholds used to define the poverty line are those of the CSIAS. The CSIAS sets the critical income threshold at $\mathrm{CHF} 23,690$ per equivalent adult. This stands in contrast with other commonly used thresholds in the European Union, determined as a given fraction of median disposable income. We note however that this threshold corresponds to 57 percent of the median equivalent household disposable income in 1998, when needs are calculated using the modified OECD scale.

It is important to note that our benchmark scenario differs from the current situation in Switzerland in one important respect. All cantons operate different types of social assistance schemes subject to means tests. Amongst the population entitled for social assistance, the take up of these allowances is however far from universal. Leu et al. (1997) in fact suggest that the non-take up rate varies considerably according to the type of benefit considered, and is somewhere in the range of 45-86 percent.

Ideally we would have wanted to model the probability of benefit take-up. However, because of data limitations, we were unable to estimate such a decision. For this reason, we assume in our base scenario that no one receives social benefits from the government. The current situation in Switzerland with regard to social assistance is therefore somewhere between our base scenario and another limiting case where the take-up rate is universal, a scenario which we have modeled below under the label inc supp. The different scenarios are summarized with the help of Table 1 and Figure 1 according to the participation condition they entail (essentially a restriction on work hours) and the underlying budget constraint (summarized by the column headings income subsidy and flat tax region). The scenarios are all constructed to be revenue neutral, meaning that they generate the same level of 


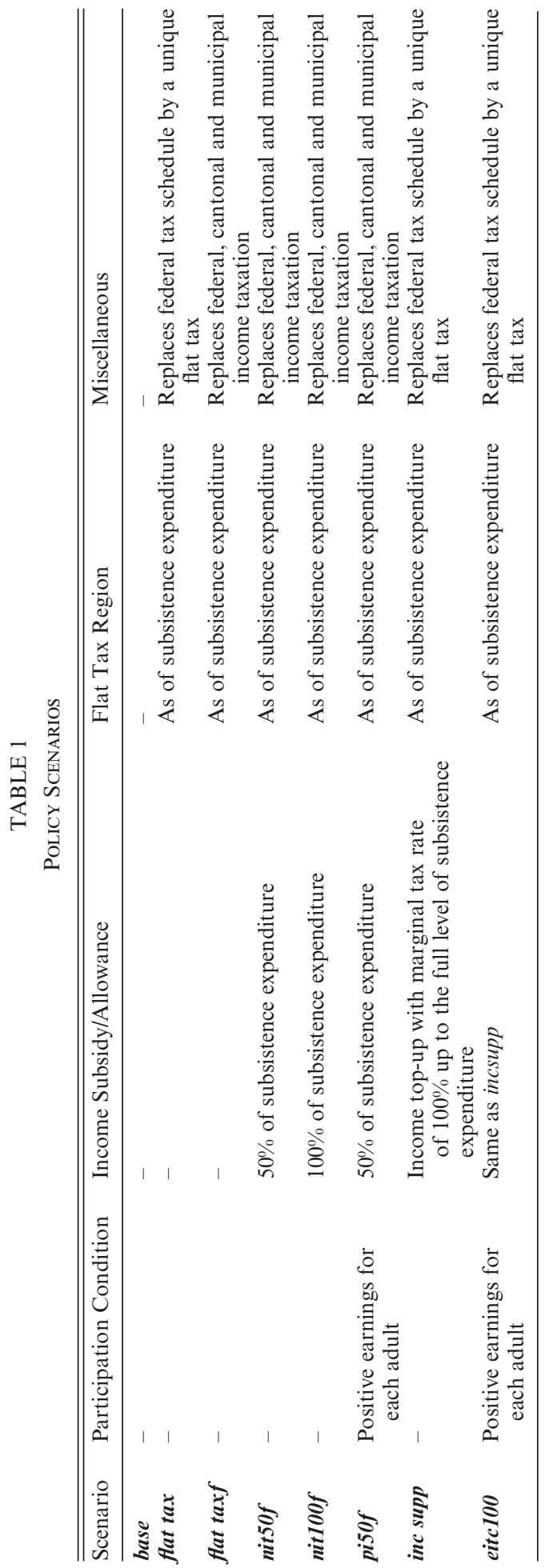




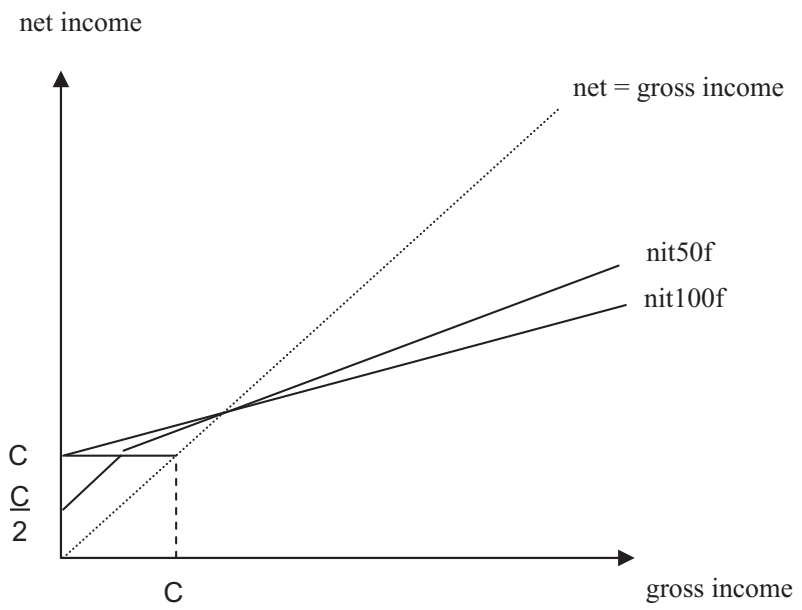

Figure 1. Budget Constraints for Partial and Full NIT Allowance Under an Integrated Linear Tax System

Note: C denotes subsistence expenditure.

tax receipts at the federal level as in the benchmark scenario, plus the revenues required to sustain the alternative income support programs.

Our scenarios can be usefully distinguished according to whether benefits are subject to an income means test, whether they are conditional on participation in the labor market (i.e. a minimum number of hours restriction), or both. Thus, eitc100 operates subject to both an hours of work requirement and an income restriction. The other polar case is scenarios which have a universal character (that do not require labor force participation, and which are not restricted to individuals on low income). There are two policy reforms of this nature: nit50f and nit $100 f$ which are two variants of the negative income tax. The scenario inc supp (an income support scheme) grants assistance to families on low income, regardless of their employment status. Conversely, pi50f is a participation income which is granted to all families that meet an hours of work requirement, irrespective of their income levels. The pros and cons of each of the scenarios from the point of view of the equity and efficiency effects they entail will be discussed later, with the results at hand.

We first consider the scenario flat taxf, intended to examine the redistributive effect of replacing the current federal, cantonal and municipal income tax structure by a single flat tax, operating as of the level of subsistence expenditure. ${ }^{3}$ There are two reasons which motivate this exercise. First, as argued by Atkinson (1995, p. 2) in the context of Britain, the tax rate required to sustain variants of the Negative Income Tax is likely to be higher than the current highest tax rates operating in Europe, so that the scope for a non-linear graduated tax schedule is indeed limited. Second, the feasibility of the envisaged tax reforms can be summarized by

${ }^{3}$ The "f" of the acronym "flat taxf" denotes the fact that a single tax would be levied at the federal level, replacing the three-level structure of the current Swiss income tax system. We use this notation for other scenarios which include such a wide-ranging fiscal reform. 
TABLE 2

Tax Reform: Summary Statistics

\begin{tabular}{lcccccrr}
\hline \hline Scenario & $\mathrm{I}_{\mathrm{A}}{ }^{1}$ & Gini & $\begin{array}{c}\text { Poverty } \\
\text { Headcount }\end{array}$ & $\mathrm{P}_{\alpha}{ }^{3}$ & $\begin{array}{c}\text { Av. Disposable } \\
\text { Income }\end{array}$ & $\begin{array}{c}\text { Flat } \\
\text { Tax Rate } t\end{array}$ & Hours $^{4}$ \\
\hline base & 0.149 & 0.211 & 0.033 & 0.002 & $0.00 \%$ & - & $0.00 \%$ \\
Panel A: & Major reforms involving & an integrated tax system & & & \\
flat taxf & 0.152 & 0.216 & 0.024 & 0.002 & $0.14 \%$ & $28.69 \%$ & $0.03 \%$ \\
nit50f & 0.084 & 0.162 & 0.011 & 0.001 & $-5.87 \%$ & $51.34 \%$ & $-6.42 \%$ \\
nit100f & 0.057 & 0.135 & 0.00 & 0.00 & $-9.25 \%$ & $62.17 \%$ & $-10.04 \%$ \\
pi50f & 0.127 & 0.189 & 0.017 & 0.002 & $0.45 \%$ & $42.09 \%$ & $0.62 \%$ \\
Panel B: Reforms involving a change in federal taxation only & & & \\
flat tax & 0.155 & 0.217 & 0.034 & 0.002 & $0.16 \%$ & $4.91 \%$ & $0.38 \%$ \\
inc supp & 0.139 & 0.219 & 0.00 & 0.00 & $-2.35 \%$ & $9.11 \%$ & $-3.21 \%$ \\
eitc100 & 0.152 & 0.215 & 0.031 & 0.002 & $-0.02 \%$ & $6.69 \%$ & $-0.03 \%$ \\
\hline
\end{tabular}

Notes:

${ }^{1}$ The Atkinson index $\mathrm{I}_{\mathrm{A}}$ sets $\varepsilon$ at 2 .

${ }^{2}$ Subsistence expenditure $=$ CHF 23690 .

${ }^{3}$ The $\mathrm{P}_{\alpha}$ index (Foster et al., 1984) sets $\alpha$ at 2.

${ }^{4}$ Relative change with respect to base case.

examining the marginal tax rate necessary to sustain the reforms under a balanced budget requirement. We also consider a variant of the above scenario, flat tax, where we only replace the current federal income tax structure by a single flat tax, operating as of the level of subsistence expenditure. This latter scenario will prove useful for assessing the desirability of reforms more limited in nature than the negative income tax, i.e. inc supp and eitc100.

Consider then the scenario nit50f in Table 2. This scenario grants households 50 percent of subsistence expenditure, but only begins to tax income as of the level of subsistence expenditure. As there are no participation conditions operating here, the scenario is intended to capture the distributive effects of what may be considered to be a negative income tax allowance covering 50 percent of household subsistence costs (as opposed to a full negative income tax scheme granting an allowance equal to 100 percent of subsistence expenditure). As is the case in flat taxf, under the scenario nit50f households are assumed to pay all their taxes at the federal level. Therefore, the graduated cantonal and federal income tax schemes are replaced by a unique linear income tax schedule, which is sketched in Figure 1. We also examine the impact of a full negative income tax scheme which we have called nit100f. The scheme therefore grants an income allowance covering subsistence expenditure. The nit $100 f$ scheme is the full negative income tax analog of nit50f, which is also sketched in Figure $1 .^{4}$

Another variant of the negative income tax package is one where a participation requirement is introduced. The participation income scheme considered here introduces a work requirement on behalf of each adult in the household. For example, under pi50 $f$ the participation income is not paid to a two-parent family in case the wife decides to stay home to take care of the children, even when the family's resources fall short of a specified poverty line. Likewise, for single parent

${ }^{4}$ For the two variants of the negative income tax, namely nit100f and nit50f, we take it that basic health insurance is financed through income taxation. 
households such as lone mothers, the scheme only covers those in paid employment. The scheme pi50f therefore mimics all features of nit $50 f$ with the participation condition added.

Finally, we have considered simulating two further social assistance packages which involve a federal tax only, keeping cantonal and municipal taxation unchanged. We have defined an income support package, inc supp, which tops up the income of every household to bring them to the level of subsistence expenditure. Until this threshold is reached, there is a one for one withdrawal of assistance for each additional franc earned, implying a marginal tax rate of 100 percent; a scheme in many respects identical to the way social assistance operates currently in a majority of Swiss cantons. ${ }^{5}$ Once the subsistence threshold is crossed, we assume that federal taxation takes the form of the linear flat tax scheme flat taxf discussed earlier. Our final policy package operates as inc supp with the additional participation requirement of positive work hours for each household member. Because this last package is in several ways similar to the American and British tax credit schemes discussed in the Introduction, we have chosen to label this last scenario eitc100.

\section{Results: An Overview}

In order to evaluate the economic effects of the scenarios outlined in the preceding section, we use a microsimulation model which combines a tax-benefit module and an econometrically estimated model of labor supply. The tax-benefit module contains detailed tax and benefit schedules for Swiss residents both at the federal and cantonal level. These schedules are used, on the one hand, to generate budget constraints for each household in the econometric estimations and, on the other hand, as a baseline for the simulation of alternative policy scenarios. In the econometric model, labor supply is modeled as a discrete choice between nonparticipation and different employment states (see Table 5). The labor supply model is specified separately for two-adult and single-adult households, using the Swiss expenditure and income survey of 1998 as database. Our sample includes 5434 family units. ${ }^{6}$

The effects on income distribution, output and employment entailed by the eight scenarios discussed above are summarized in Table 2. There are two sets of results: Panel A results refer to reforms involving an integrated tax system replacing the existing three levels of taxation. Panel B results pertain to reforms involving a change in federal taxation only. For each scenario we report inequality statistics (Atkinson and Gini indices) and poverty statistics (head-count and Foster et al. $P_{\alpha}$ indices). We also report for the various scenarios the relative variation in average

${ }^{5}$ A100 percent marginal tax rate describes quite precisely the social assistance system in 1998 when the ERC survey was carried out. More recently, several cantons have introduced a small incentive to take up work by exonerating the first several hundred francs earned per month. However, these modest reforms have worsened the situation of those who plan to leave the social assistance system altogether; in this situation marginal tax rates well above 100 percent can be observed in several cantons. These more complicated schemes could not be taken into account in our simulations since data limitations prevented us from modeling the take-up decision, as mentioned above.

${ }^{6}$ See the appendix of Abul Naga et al. (2007) for a detailed description of the microsimulation framework. 
disposable income and in total hours of work. We also present the value for the flat tax rate $t$ required to sustain the various social insurance schemes under the assumption of revenue neutrality discussed above. Before we turn to the results, we briefly discuss the choice of poverty and income distribution indicators.

\subsection{A Note on the Choice of Inequality and Poverty Indices}

The Gini coefficient is presented here due to its wide appeal amongst practitioners and government statistical bureaus. While the Gini index satisfies the Pigou-Dalton principle of social aversion to inequality, this index presents a drawback in the sense that the underlying social welfare function is quasi-concave, but not strictly so. For this reason the social marginal utility of income to a household underlying the Gini index depends only on its rank, rather than the level of its resources. In practice, the Gini index will be more sensitive to income changes in the middle of the distribution rather than in the tails. The Atkinson index (Atkinson, 1970) does not present this drawback of the Gini. Furthermore, in case sub-group decomposable measures of inequality are required, the Atkinson index can be used, whereas the Gini index is not easily decomposable.

The poverty headcount is a useful summary statistic indicating the population share living below the poverty line. However it conveys no information about the depth of the problem, and it is insensitive to the distribution of resources among the poor. For this reason, we supplement the head-count with the Foster et al. (1984) measure $P_{\alpha}$, which offers a remedy for both problems for values of $\alpha>1$.

\subsection{Policy Effects: Summary Statistics}

Our summary statistics here pertain to the resulting distributions of household disposable income. The income concept used is the equivalized household income; needs being calculated according to the CSIAS equivalence scale discussed above. ${ }^{7}$ Our benchmark scenario base entails a level of inequality of 0.15 when using the Atkinson index and 0.21 using the Gini coefficient. ${ }^{8,9}$ The poverty headcount $H$ takes on a value of 0.033 while the $P_{\alpha}$ index takes on a value of 0.002 . To examine the effect of replacing all taxation with a flat tax rate, other things held constant, we examine the flat taxf scenario. The results (first line of Panel A) indicate that the introduction of an integrated flat tax would result in a marginal tax rate of 28.69 percent. There is a marginal increase in inequality, with a 1 percent decline in the poverty headcount. ${ }^{10}$ There is a 0.14 percent increase in average disposable income, and virtually no change in total hours worked.

Next, we turn to nit50f, the partial negative income tax allowance. In comparison to the introduction of a flat tax scheme alone, the combined partial

${ }^{7}$ In the calculation of summary statistics, the household data are weighed according to sample weights provided by the ERC survey.

${ }^{8}$ The calculations pertaining to poverty and inequality have been undertaken using the software DAD 4.4 (see Duclos et al., 2005).

${ }^{9}$ The calculations for the Atkinson index here set the inequality aversion parameter $\varepsilon$ at 2 ; for the calculations of the Foster et al. index we set $\alpha$ at 2.

${ }^{10}$ This decline in poverty results from the fact that in the base scenario the poor are not exempted from taxation in all cantons. Under the present scenario all incomes below the poverty line are exempt from taxation. 
negative income tax allowance and flat tax has a pronounced effect on income inequality and poverty. Taking nit $50 f$, we may note a 44 percent drop in the level of the $I_{A}$ index, in comparison to the benchmark scenario base. There is also a 24 percent drop associated with the Gini (a decline from 0.21 to 0.16 ). The resulting poverty head-count drops from 3.3 percent to 1.1 percent. Likewise, for the $P_{\alpha}$ index there is also a substantial 50 percent drop from 0.002 to 0.001 . The envisaged scenario is shown however to entail a heavy tax burden: in comparison to the 28.7 percent marginal tax rate of flat taxf, households above the subsistence resource level would face a federal marginal tax rate of 51 percent under nit50f. The welfare gains from increased equality have therefore to be weighted against the efficiency effects they entail: our microsimulation results indicate a resulting 5.9 percent reduction in disposable income and a 6.4 percent decline in total hours worked in comparison to the base scenario.

Next consider the full negative income tax allowance, nit100f. Of the eight schemes considered here nit $100 f$ allows for the largest drop in inequality. The Atkinson index takes a value of 0.06, and the Gini 0.14. In its current form, the proposed scheme is excessively costly to operate: the federal tax rate required to sustain nit $100 f$ is equal to 0.62 . Again, the equality gains resulting from the above social insurance scheme have to be weighed against their efficiency costs: nit 100f entails a 9.3 percent reduction in disposable income and 10 percent reduction in work hours. It is also instructive to compare the full negative income tax scheme with its partial negative income tax allowance counterpart: nit $100 f$ entails an integrated marginal tax rate of 0.62 whereas nit $50 f$ was sustainable at $t=0.51$. While nit50f does not eliminate all poverty, it results in a limited 5.9 percent sacrifice in terms of average disposable income, whereas, as stated earlier, nit $100 f$ entails a 9.3 percent loss of average income.

The next scenario we examine operates under a participation requirement for all working age adults. This participation income scheme is not intended to reduce social exclusion-it typically excludes non-participants in the labor market. Instead, its purpose is to induce participation. The pi50f scheme is the analog of nit50f, with the participation condition added. It is therefore instructive to compare the performances of pi50 $f$ and nit50f in equity and efficiency terms. While nit $50 f$ entails a 6.4 percent reduction of work hours, there is a 0.6 percent increase of hours under the latter scheme. Our microsimulation results suggest that pi50f is sustainable at an integrated flat tax rate of 0.42 , whereas $t$ was found to equal 0.51 under nit50f. The variant with a participation requirement however entails degrees of inequality not far from those of the benchmark scenario base. The Gini for instance equals 0.19 under pi50f, 0.21 under base, but is considerably lower, 0.16 , under nit50f. It is to be noted also that pi50 $f$ does not reduce the poverty headcount to the level achieved by the nit50f reform.

Under Panel B we examine more limited reforms involving a change in federal taxation only. The analog of flat taxf is a scenario flat tax which replaces the existing federal income tax schedule (a tax schedule involving a large interval of exemption followed by a steeply rising average tax rate) with a flat tax levied as of subsistence expenditure. The existing cantonal and municipal taxes however remain unchanged. The resulting marginal tax rate of 4.9 percent (first line of Panel B) highlights the limited nature of the reform involved. There inequality rises 
because with a marginal tax rate of 4.9 percent the resulting tax schedule is less progressive than the federal tax schedule of the base scenario. The level of poverty is virtually unchanged. There is a 0.16 percent increase in average disposable income, and a 0.4 percent increase in hours worked.

Our inc supp scenario is designed with the specific purpose of eliminating poverty by targeting resources exclusively to those below the subsistence poverty line, and by granting poor families only the top up required to reach the subsistence level. It comes therefore with little surprise that such a finely targeted scheme achieves the 0 percent poverty level at a federal tax rate of only 9.1 percent. We devote a sub-section below to a critical examination of the relative merits of operating such a scheme.

The final scheme we considered is a variant of the above scheme designed to correct for the disincentive effects related to inc supp. The earlier scheme is thus kept in all respects unchanged, except now that every working age adult is required to supply a positive amount of hours in order for the household to benefit from social assistance. The resulting scheme eitc100, is operational with a linear tax rate of 6.7 percent, and results in a minor ( 0.03 percent) decline in hours worked. ${ }^{11}$ Again, the incentive effects induced by such a scheme have to be judged in the light of its less successful performance in terms of income redistribution. Our summary measures indicate that the eitc100 scheme results in an increase of inequality over the benchmark scenario, and entails higher levels of poverty than all other reform scenarios. Again, the main reason for this finding is due to the fact that the resulting federal income tax scheme, with a marginal tax rate of 6.7 percent, is considerably less progressive than that of the base scenario.

\subsection{Policy Effects: $A$ Word of Caution}

It is to be noted that many of the critiques voiced against the targeting approach (for instance Sen, 1995) apply in the context of the operation of the inc supp scheme: namely it is assumed that household resources are observed accurately, that there is no stigma to applying for assistance, no administrative costs to evaluating household resources and finally that targeting type I and II errors are in existent (see Goodin, 1985 for a discussion).

The results of Table 2 may easily lead the policy maker to conclude that the income support scheme is most preferable given that it eliminates poverty with a moderate 9 percent flat tax scheme, and a 2.4 percent loss in average disposable income. However, bearing in mind that at the chosen level of the poverty line very few people with very uncommon circumstances are in poverty, a word of caution is required here. In Figure 2, we plot the poverty headcount against the poverty line for various policy scenarios. One pattern clearly emerges when comparing the overall performances of the four scenarios examined there: the inc supp scheme clearly eliminates poverty up to the retained level of subsistence expenditure. However, the poverty headcount immediately jumps to well over 5 percent (a

${ }^{11}$ Although the participation condition of the eitc100 scheme encourages individuals outside the labor force to take up work, this reform provides also an incentive for working individuals (especially secondary earners) to reduce the number of hours worked. Here the latter effect obviously prevails over the former. 


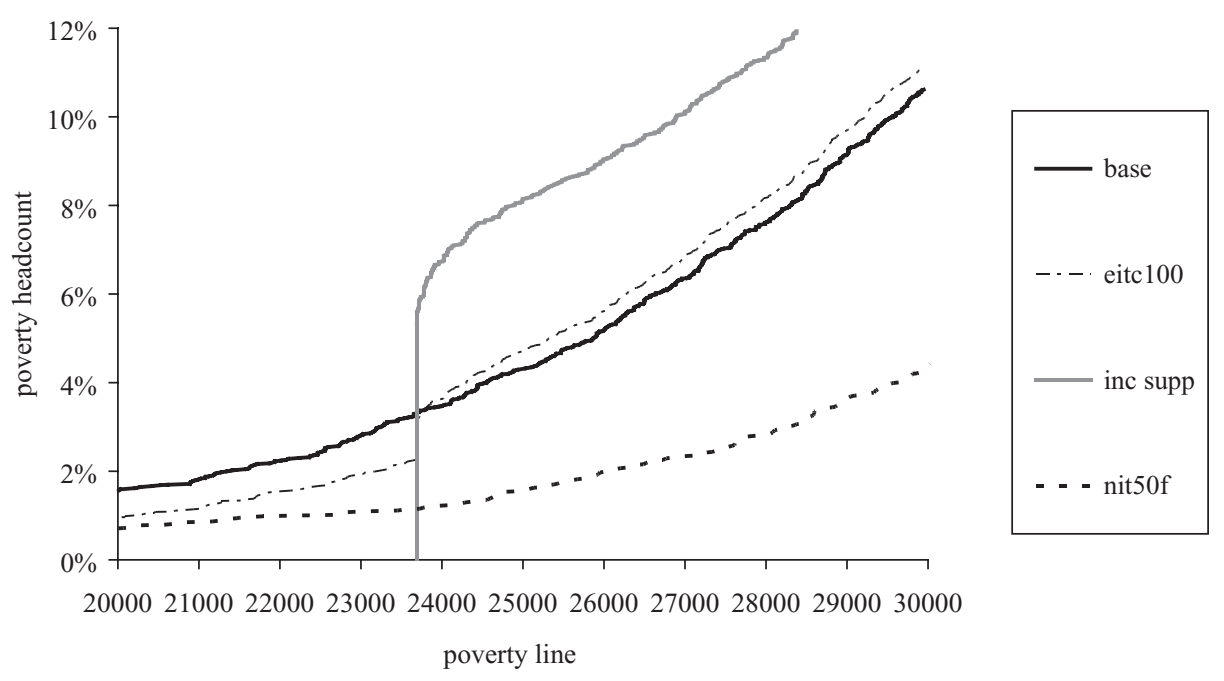

Figure 2. Poverty Rates in Four Policy Scenarios

higher level than in all other scenarios) for poverty lines above the pre-specified income threshold. The reason for this finding is the well documented poverty trap induced by an income support scheme operating a 100 percent marginal tax rate on all income earned below the subsistence poverty line, leading many households to stop working altogether. ${ }^{12}$

This somewhat undesirable feature of inc supp occurs to a lesser extent in the context of eitc100. The latter scheme does not eliminate poverty entirely at the level of subsistence expenditure; however the jump in the poverty headcount which occurs above the specified poverty threshold is smaller in size than is the case in the context of the earlier scheme. The negative income tax scheme nit50f, while costly to administer, entails a lower level of head-count poverty than the base scenario, eitc100, and inc supp once we consider poverty lines above the retained subsistence expenditure level. It is in this sense necessary to examine the overall distributive impact of the various policy scenarios, not just around a pre-specified poverty line. We turn to such considerations in the section below.

The analysis of inequality also yields intriguing results. Moving from the benchmark scenario to inc supp, the Atkinson inequality index of Table 2 indicates a decline, whereas the Gini index records a rise, in the level of inequality. This result is best apprehended by recalling that, on the one hand, inc supp redistributes resources to those at the bottom end of the distribution and, on the other hand, a substantial share of households in the middle of the distribution see their income decrease because they cease to work. The Atkinson index is more sensitive to the former effect and the Gini index to the latter. These results demonstrate the importance of a more general approach to income inequality comparisons. This is the issue of the next section.

\footnotetext{
${ }^{12}$ The participation rate of single adult households drops from 90.6 percent in the base scenario to 83.1 percent in inc supp. Moreover, the share of couples who work zero hours increases from 0.7 percent in the base scenario to 1.7 percent in the inc supp scenario.
} 


\section{Changes in Income Distribution: An Ordinal Analysis}

The various scenarios analyzed above were shown to redistribute income and to alleviate poverty to differing extents. They were also shown to have different impacts on hours worked and average income. ${ }^{13}$

It is necessary however to complement the results of Table 2 by taking a further look at the data. Questions such as what happens to income inequality if we choose to use an alternative inequality index to the Gini and Atkinson measure need to be addressed. Similarly, depending on the budget constraints they entail, the various policies may redistribute resources differently at the bottom, middle and top of the income ladder. In this respect, the use of graphical devices involving transformations of the cumulative distribution function will usually provide richer information on the extent of redistribution, than an examination of poverty and inequality summary measures.

To address these issues, in this section we examine the distributional impact of the set of policy scenarios from an ordinal perspective. ${ }^{14}$ That is, taking one pair of distributions at a time, we examine the usual dominance conditions on the respective Lorenz curves pertaining to these scenarios which guarantee a change in inequality of the same sign for all inequality indices that satisfy the Pigou-Dalton transfer principle (Section 4.1). Likewise for the class of poverty indices which obey the Pigou-Dalton transfer principle, we examine related dominance conditions on the pattern of specific pairs of poverty deficit curves which guarantee that all poverty measures rank two specific scenarios in a similar fashion (Section 4.2). Section 4.3 addresses the question as to which of the five envisaged reform scenarios may be seen to entail a level of social welfare superior to the current status quo scenario in Switzerland. Following Shorrocks (1983), the social welfare concept may be seen here as an approach unifying considerations of equity and efficiency.

\subsection{Income Inequality}

The Lorenz curve is typically used to depict information on income inequality, but also, to check for inequality orderings. When the Lorenz curve for a distribution $F_{A}$ lies everywhere above that of $F_{B}$, then all inequality indices that exhibit a social aversion to inequality will rank $F_{A}$ as the more equal distribution. Table 3 summarizes the information regarding the 15 pair-wise comparisons between the six scenarios mentioned above. If the Lorenz curve for $F_{A}$ lies everywhere above that of $F_{B}$, then this information can be conveyed by plotting the difference between the Lorenz curves of these two distributions. The resulting curve should have an inverted $U$ shape. Figure 3 presents such plots for differences in Lorenz curves between selected scenarios.

\footnotetext{
${ }^{13}$ Clearly, the welfare loss resulting from a reduction in average income and in hours worked under certain scenarios may be partly offset from the welfare gains arising from additional consumption of leisure. Our primary interest here being on the changes in poverty and inequality, we do not take up this issue further. Regarding this point see Aaberge et al.(2004) and Kornstad and Thoresen (2006) for further details.

${ }^{14}$ In what follows, the scenarios flat tax and flat taxf are dropped from the analysis.
} 
The first line of Table 3 contains comparisons between the benchmark scenario base and the other retained scenarios. The cell (base, nit100f) has a + sign, signifying that the benchmark scenario exhibits more inequality than nit $100 f$ in a Lorenz dominance sense. The cell (base, inc supp) conveys the information (+, $p=1$ ) indicating that the underlying Lorenz curves cross at the first income decile, with the Lorenz curve of the benchmark scenario lying below prior to the intersection, and above from the second to ninth decile. As the inc supp program is targeted to top up the resources of families living below the poverty line, this result is indeed expected. With crossing Lorenz curves, a summary measure which is sufficiently sensitive to inequality at the bottom of the distribution, may rank inc supp as the more egalitarian of the two scenarios. This is why the Atkinson index indicates that inc supp is more favorable than the benchmark scenario from the perspective of income inequality. There is a similar crossing of Lorenz curves between the benchmark scenario and eitc100, even though the latter does not provide the income top up to families where both adults do not work. The next two

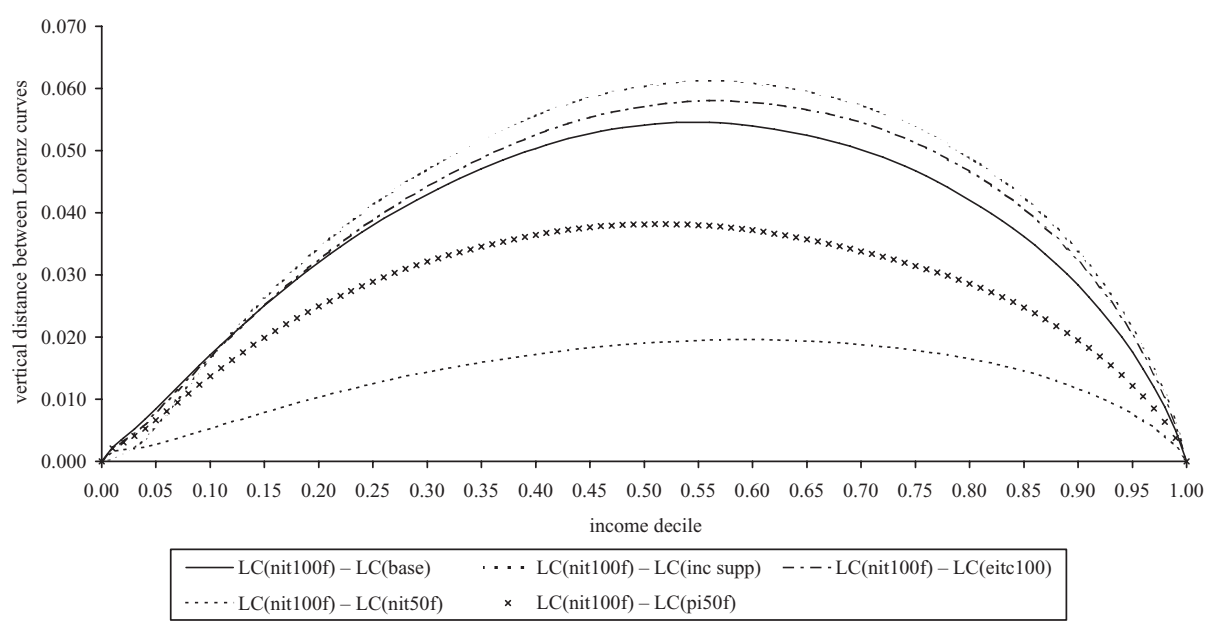

Figure 3. Full Negative Income Allowance Redistributive Impact

TABLE 3

INEQUALITY ORDERINGS

\begin{tabular}{|c|c|c|c|c|c|c|}
\hline Scenario & base & nit100f & inc supp & eitc100 & nit50f & pi50f \\
\hline base & & + & $\begin{array}{l}+ \\
p=1\end{array}$ & $\begin{array}{l}+ \\
p=1\end{array}$ & + & + \\
\hline nit100f & - & & - & - & - & - \\
\hline inc supp & $\begin{array}{l}- \\
p=1\end{array}$ & + & & $\begin{array}{l}- \\
p=1\end{array}$ & + & $\begin{array}{c}- \\
p=0.6\end{array}$ \\
\hline eitc100 & $\begin{array}{l}- \\
p=1\end{array}$ & + & $\begin{array}{l}+ \\
p=1\end{array}$ & & + & + \\
\hline nit50f & - & + & - & - & & - \\
\hline$p i 50 f$ & - & + & $\begin{array}{c}+ \\
p=0.6\end{array}$ & - & + & \\
\hline
\end{tabular}

Note: $\left(F_{i}, F_{j}\right)=(-, q)$ means $F_{i}$ is less unequal than $F_{j}$ up to $q$-th decile. 
cells indicate that the benchmark scenario exhibits more inequality than both variants of the partial negative income tax allowance retained, namely nit50f and pi50f. In this sense, our results show an unambiguous effect of inequality reduction when operating a full NIT allowance, a partial NIT allowance or a (partial) participation income.

It is not without interest to compare also the scope for redistribution between the various policy scenarios. The second line of Table 3 indicates that the Lorenz curve of nit $100 f$ lies everywhere above that of the other five scenarios examined in this section. The cost of operating such a scheme (a flat tax rate of 0.62 and a 9.3 percent loss of average disposable income) may be evaluated in the light of the gains in income redistribution. Figure 3 plots Lorenz curve differences between nit100f and base, and between nit100f and each of inc supp, eitc100, nit50f and pi50f. It is to be noted that all curves have the inverted $U$ shape discussed earlier, with the extent of redistribution being more pronounced when moving from a partial NIT allowance nit50f to a full NIT allowance. The reductions in income inequality in moving from either the benchmark scenario, inc supp or eitc100 to the negative income tax allowance are however substantial. As is most often the case, the extent of redistribution is usually largest for the middle income groups (see for instance Davidson and Duclos, 1997). Consider for instance the transition from the base scenario to nit100f. There, at the fifth decile, there is a redistribution of 6 percent of total income from the richer to poorer groups.

The third to sixth lines of Table 3 compare the remaining policy scenarios. It may be noted that the participation requirement introduced in eitc100 makes this scenario less egalitarian than inc supp for the bottom income decile. The distribution entailed by the partial NIT allowance nit50f Lorenz dominates all other distributions with the exception of the distribution related to the full NIT allowance. The distribution resulting from the operation of the participation income is Lorenz dominated by the distributions pertaining to nit100f and nit50f, as discussed earlier. However pi50f Lorenz dominates eitc100. As a consequence of the participation requirement, the Lorenz curve pertaining to pi50f lies below that of inc supp up to the 4th percentile $(p=0.6)$; the inequality ranking of these two distributions will therefore not be robust to the choice of inequality index.

\subsection{Poverty}

The poverty headcount in our sample takes a value of 0.033 under the base scenario. This figure is low because there is comparatively less poverty in Switzerland than in other European countries, but also because our sample excludes the elderly and self-employed populations. As such, it would be somewhat misleading to judge the overall performance of our various policy scenarios in the light of one single poverty line which identifies very few cases as being in a state of deprivation. We check therefore for potential crossings of poverty deficit curves (the first cumulant of the cumulative distribution function), where we consider all poverty lines ranging from zero to 50,000 Swiss francs (i.e. 210 percent of the CSIAS poverty threshold). When the poverty deficit curve for a distribution $F_{A}$ lies every- 
TABLE 4

Poverty Orderings $(Z \in[0 ; 50,000])$

\begin{tabular}{|c|c|c|c|c|c|c|}
\hline Scenario & base & nit100f & inc supp & eitc100 & nit50f & $p i 50 f$ \\
\hline base & & $\begin{array}{c}+ \\
\text { everywhere }\end{array}$ & $\begin{array}{c}+ \\
\text { up to } 27,550\end{array}$ & $\begin{array}{l}\text { +up to } 6,260 \\
\text {-up to } 12,760 \\
\text { +up to } 31,930\end{array}$ & + & $\begin{array}{l}- \\
\text { up to } 12,900 \\
+ \text { after }\end{array}$ \\
\hline nit100f & $\begin{array}{c}- \\
\text { everywhere }\end{array}$ & & $\begin{array}{c}- \\
\text { everywhere }\end{array}$ & $\begin{array}{c}- \\
\text { everywhere }\end{array}$ & - & - \\
\hline inc supp & $\begin{array}{c}- \\
27,550\end{array}$ & $\begin{array}{c}+ \\
\text { everywhere }\end{array}$ & & $\frac{-}{26,740}$ & $\begin{array}{c}- \\
\text { up to } 24,870\end{array}$ & $\begin{array}{c}- \\
\text { up to } 25,440\end{array}$ \\
\hline eitc100 & $\begin{array}{r}-6,260 \\
+12,760 \\
-31,930\end{array}$ & $\begin{array}{c}+ \\
\text { everywhere }\end{array}$ & $\stackrel{+}{26,740}$ & & + & + \\
\hline nit50f & - & + & $\stackrel{+}{{ }^{+}}=$ & - & & - \\
\hline$p i 50 f$ & $\begin{array}{r}+12,900 \\
\text {-after }\end{array}$ & + & $\begin{array}{c}+ \\
\text { up to } 25,440\end{array}$ & - & + & \\
\hline
\end{tabular}

Note: $\left(F_{i}, F_{j}\right)=\left[-, z_{0}\right]$ means $F_{i}$ has less poverty than $F_{j}$ for all poverty lines in the $\left[0 ; z_{0}\right]$ interval.

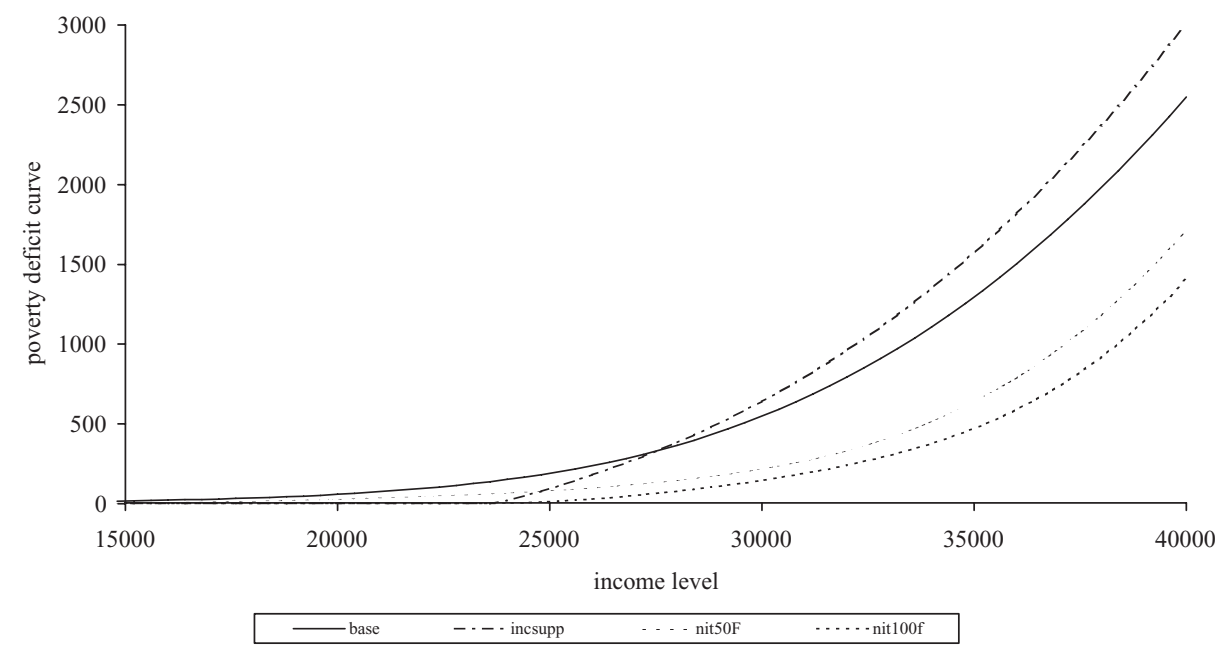

Figure 4. Poverty Deficit Curves for Four Policy Scenarios

where in this income domain below that of $F_{B}$, then all poverty indices that exhibit a social aversion to inequality will rank $F_{A}$ as the socially preferred distribution, within the range of poverty lines under consideration.

Table 4 reports the 15 pair-wise scenario comparisons from an ordinal poverty perspective. The first line of Table 4 indicates that the distribution of the base scenario entails more poverty than the distributions pertaining to the two variants of the NIT allowance. It also comes out clearly from the second line of Table 4, and Figure 4, that the full NIT allowance nit $100 f$ outperforms all other income schemes in reducing poverty. Note also that the deficit curve of the partial NIT allowance scheme lies in the income range of interest everywhere below the deficit curves pertaining to base, eitc100 and pi50f. 
It is also clear that inc supp will eliminate poverty up to the threshold (here $\mathrm{CHF}$ 23690) where the income top up ceases to operate. However, the incentive effects of such a scheme are such that its deficit curve cuts from below the deficit curve of the base scenario at CHF 27550. Its deficit curve intersects the deficit curve of eitc100 at CHF 26740, that of nit50f at CHF 24870 and that of pi50f at CHF 25440. As discussed in Section 3.3, once we vary the level of the poverty line, there is therefore scope for ranking inc supp and other scenarios (with the exception of nit $100 f$ ) differently depending on the choice of distributionally sensitive poverty measures.

Of related interest is the performance of the participation income in relation to inc supp and eitc100 in reducing poverty. For all poverty lines considered here, the deficit curve pertaining to pi50f lies below that of eitc100. Both schemes require participation in the labor market in order to qualify for social assistance, while inc supp does not. This partly explains why the deficit curve of pi50f cuts that of inc supp from above.

\subsection{Social Welfare}

This final section attempts to synthesize the previous findings by asking the question as to which scenarios present a social welfare improvement over the current situation in Switzerland. We have seen that the full NIT allowance scheme nit $100 f$, while eliminating poverty and bringing inequality to it slowest level in the findings of Table 2, entails an important cost in terms of income loss (a 9.3 percent reduction of average disposable income). The question regarding the social welfare test is therefore important to address, especially in the face of general skepticism about the feasibility of NIT allowance and flat tax proposals.

In order to weigh the gains from redistribution against efficiency losses, it is useful to summarize distributions by means of social welfare functions which satisfy a social aversion to inequality axiom (Pigou-Dalton transfer principle), and one of preference for higher incomes. Akin to the Lorenz curve, the generalized Lorenz curve is typically used to test for social welfare orderings: when the generalized Lorenz curve for a distribution $F_{A}$ lies everywhere above that of $F_{B}$, then all social welfare indices that exhibit a social aversion to inequality and a preference for higher incomes will rank $F_{A}$ as socially preferred. As shown by Shorrocks (1983), it is also the case that the generalized Lorenz criterion is biased toward efficiency preference: $F_{A}$ cannot dominate $F_{B}$ if the mean of the former distribution is lower than that of the latter.

An examination of the fifth column of results in Table 2 is particularly informative in this sense, since it shows that with the exception of the participation income pi50f, all policy reform scenarios considered in this section entail losses of total income in comparison to the benchmark scenario. It is nonetheless useful to examine the social welfare effects of the various schemes considered in this section, even though it is clear now that the only likely candidate for passing the social welfare test is pi50f.

If the generalized Lorenz curve for $F_{A}$ lies everywhere above that of $F_{B}$, up to, say the $q$ th income decile, then this information can be conveyed by plotting the difference between the generalized Lorenz curves of these two distributions. The 


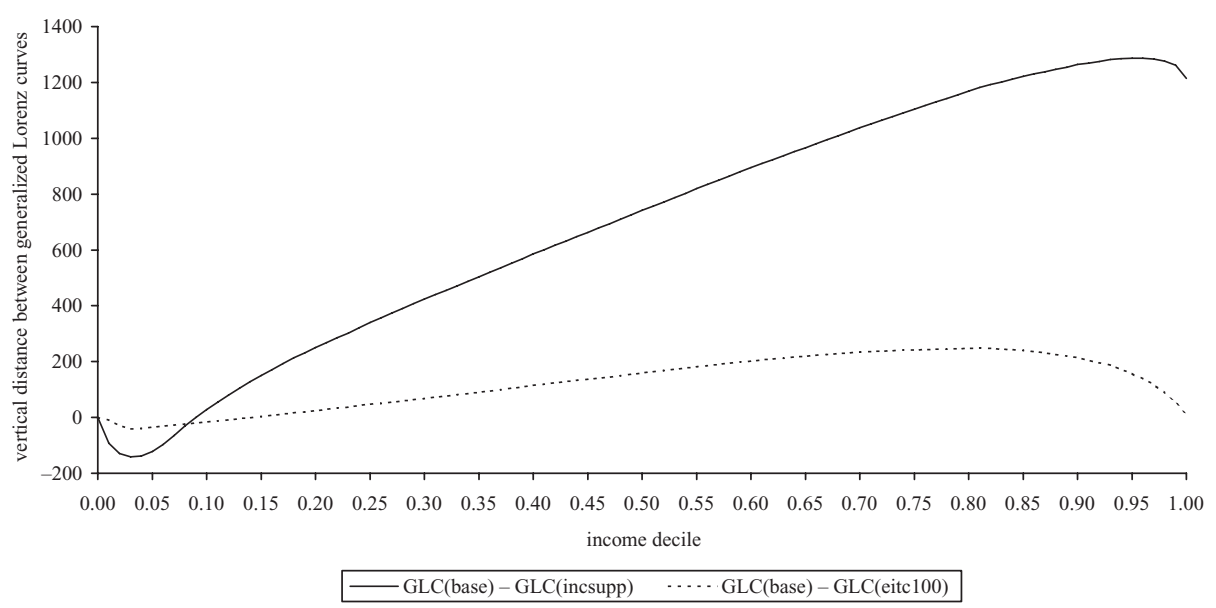

Figure 5. Social Welfare Test Base Scenario Versus Income Support and EITC100

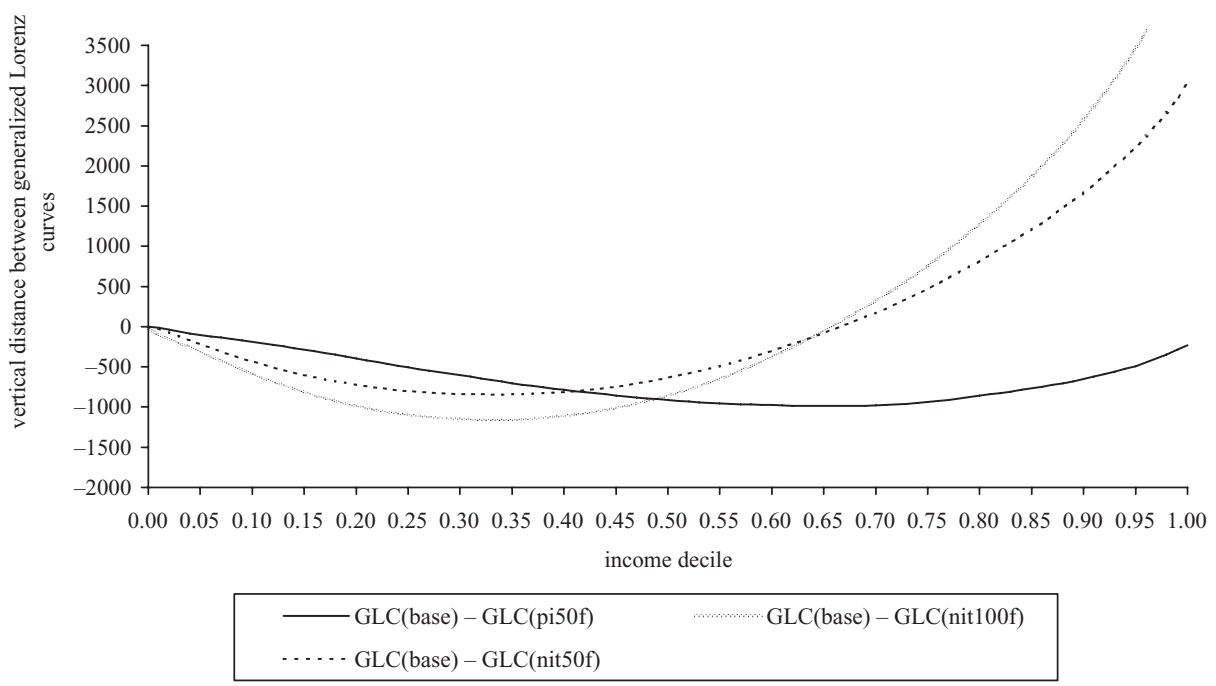

Figure 6. Social Welfare Test Base Scenario Versus Three Variants of the Basic Income

resulting curve should initially lie in the positive domain of the vertical axis, should cut the origin at the $q$ th decile, and from then on should lie in the negative domain of the vertical axis. Such a graph would also indicate that the social welfare of families belonging to the bottom $q$ income deciles is higher in $F^{A}$ over $F^{B}$. Figures 5 and 6 provide such plots of vertical differences in generalized Lorenz curves, of the type $G L C($ base; $q)-G L C(j, q)$, where $j$ is the vector of incomes pertaining to one of the remaining five scenarios.

In Figure 5 we provide plots for two comparisons, between the base scenario, and each of inc supp and eitc100. Both curves are initially below zero. The curve GLC (base; $q)$ - GLC (inc supp; $q)$ crosses the zero horizontal line halfway between 
the fifth and tenth percentiles. The curve GLC(base; q)-GLC(eitc100; q) is however closer to the zero horizontal line up to the fourteenth income percentile. These findings may readily be seen as confirming the results previously reported in Table 4. There, we had reported (i) that inc supp dominates base for all poverty lines ranging from zero to $\mathrm{CHF} 27550$, and that (ii) the eitc100 deficit curve cuts that of base a first time from below at CHF 6260, from above at $\mathrm{CHF} 12760$, and a final time, from below, at $\mathrm{CHF} 31930 .{ }^{15}$ The welfare improvements obtained from these income maintenance schemes therefore essentially accrue to the bottom groups, but not to the entire population.

Figure 6 contains remaining plots when the benchmark scenario is compared to the full NIT allowance, the partial NIT allowance and the participation income. For the bottom 65 percent of the population, nit $100 f$ and nit50f entail welfare improvements over base. The heavy tax burdens entailed by these two schemes, and the resulting effect on work hours contribute to the negative finding with respect to the overall level of social welfare. The participation income on the other hand, while not achieving the same level of effectiveness in reducing poverty and inequality, does not result in losses of average disposable income. The remaining graph of Figure 6 lies in the negative orthant of the vertical axis, indicating that the income distribution pertaining to the participation income pi50f social welfare dominates the benchmark scenario.

\section{Participation Income Reexamined}

We have seen in the above section that, out of all reform scenarios considered in the study, pi50 $f$ was the only reform leading to a social welfare improvement over the base scenario. In order to understand this finding, it is instructive to examine how households respond to the participation condition underlying the policy scenario pi50f. To do so, we plot in Figures 7 and 8 the changes in tax burdens underlying respectively the nit50f and pi50f schemes. The horizontal axis reports the disposable income of the base scenario, while the vertical axis measures the difference in tax payments in moving from the base scenario to nit50f (Figure 7), and the change in tax burdens in moving from base to pi50f (Figure 8). Positive values along the vertical axis indicate that a household pays more tax under a given scheme than in the base scenario.

A comparison of Figures 7 and 8 highlights several phenomena. First, a positive slope of the data scatter indicates that the tax-benefit scheme in the reform scenario is globally more progressive than in the base scenario. The steeper slope of the data underlying nit50f confirms our earlier conclusion that this scenario is more redistributive than pi50f. Second, the data of Figure 8 are more compactly distributed along the middle horizontal line (the locus of zero change in tax burdens). There are two main clusters in the data generated by the pi50f scenario. The upper left cluster pertains to households who fail to qualify for the income allowance. Third, the data points are more spread out below the main cluster in Figure 7, whereas they are more evenly distributed, below and above the two main

\footnotetext{
${ }^{15} \mathrm{It}$ is to be noted that in the sample there are only two households with incomes below CHF 6260 and an additional 13 with incomes short of CHF 12760.
} 


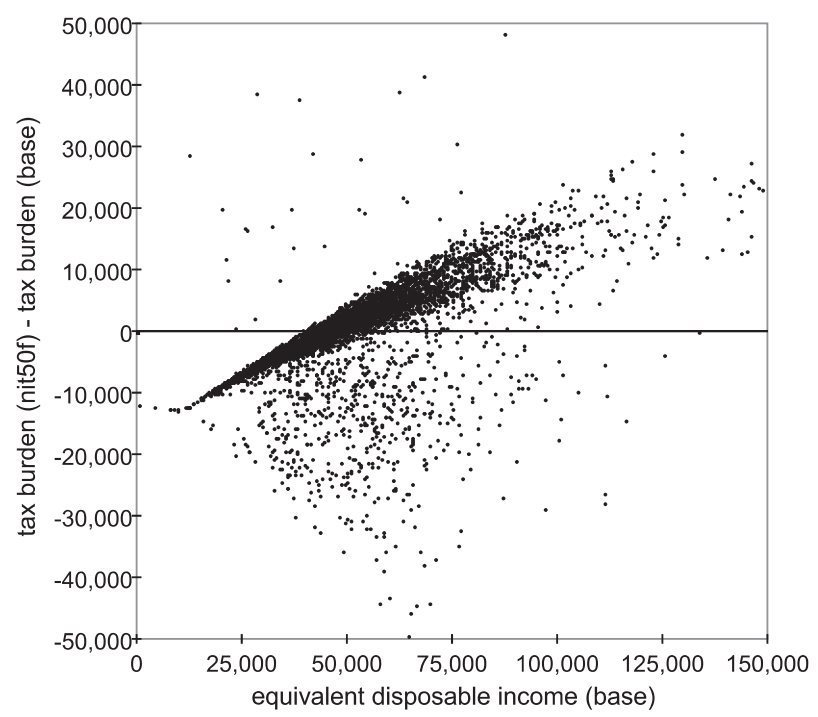

Figure 7. Change in Tax Burden (nit50f-base)

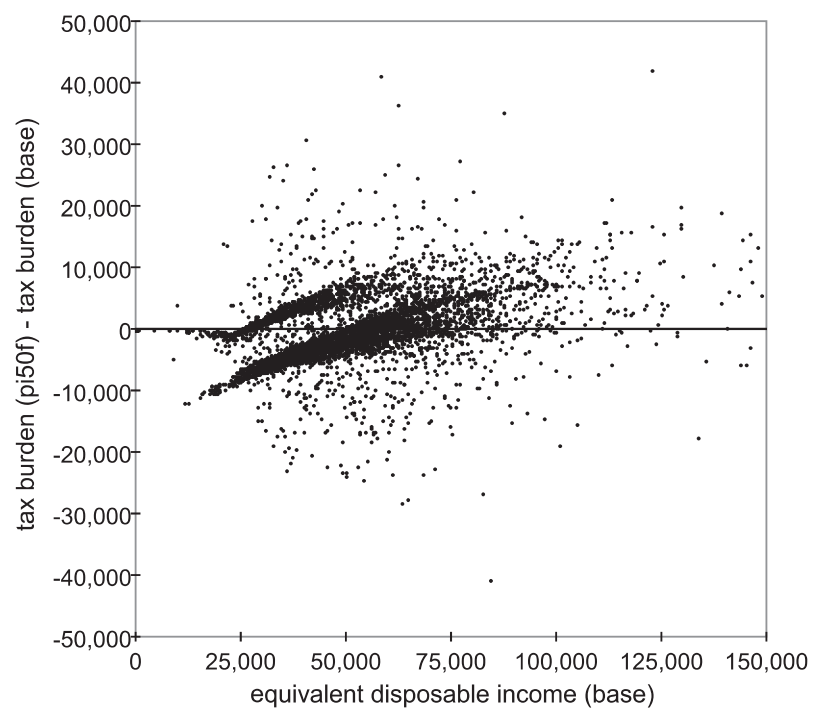

Figure 8. Change in Tax Burden (pi50f-base)

clusters, in Figure 8. As hourly wages are held fixed across scenarios, this is indicative of different labor supply responses in the two scenarios, an issue to which we turn now.

Figure 9 depicts histograms of the change in labor supply by households, measured in terms of yearly hours worked by household members. Although most households do not change their work behavior when the reforms are introduced (zero hours changes are not plotted in the histograms), there is a striking difference 

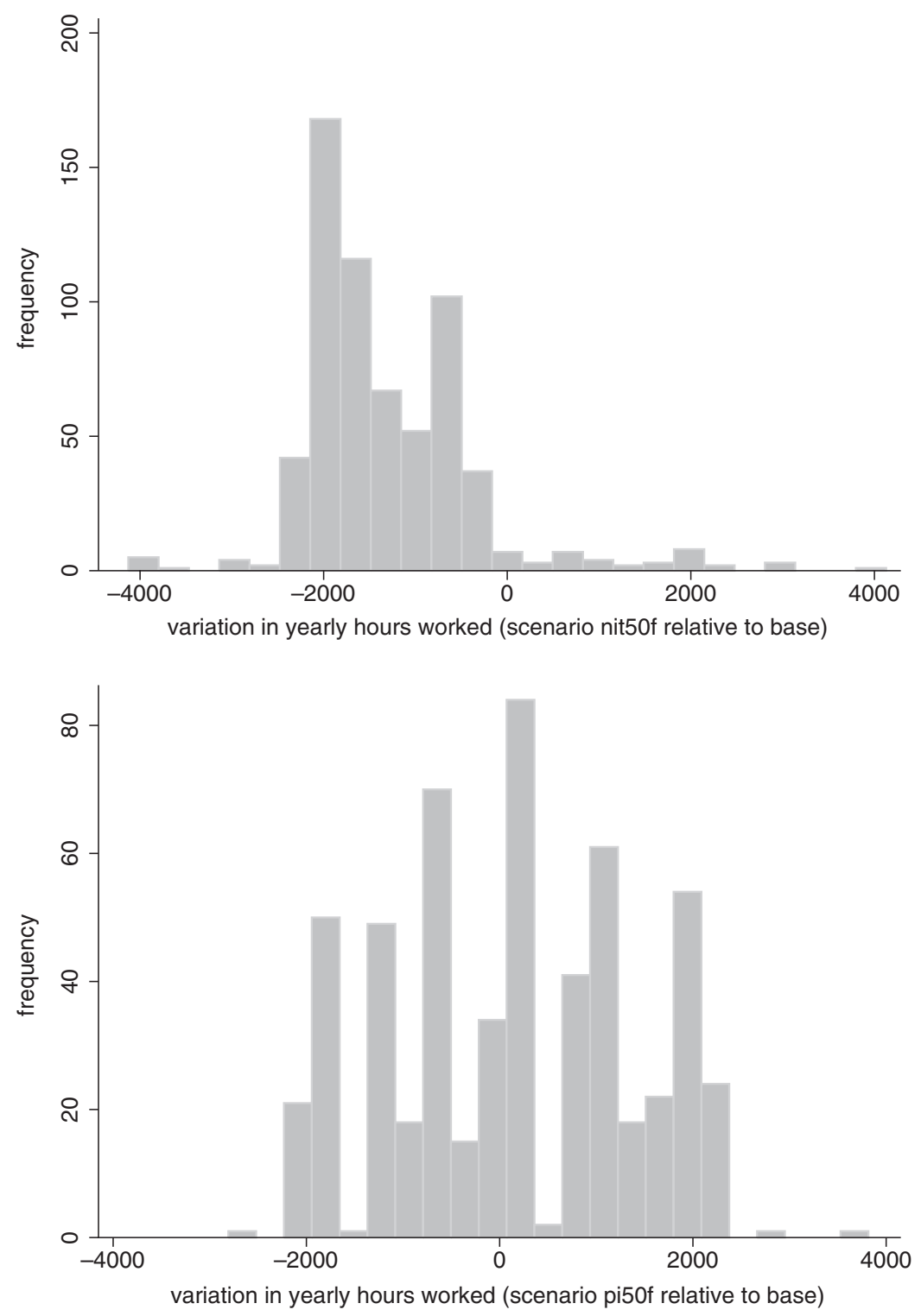

Figure 9. Histogram of Changes in Yearly Work Hours (scenarios nit50f and pi50f relative to base)

Note: Data plots refer only to households who experience non-zero changes in hours of work. In scenario nit50f (pi50f), they represent 11.7 percent of all households (10.4 percent).

between the two scenarios with respect to the behavior of those who adjust their labor supply. Whereas households almost exclusively reduce their hours of work in the nit50f scenario, the histogram of the changes in hours in the pi50f scenario is roughly symmetric around zero. The latter result indicates that there is a considerable amount of heterogeneity in individual behavior which underlies the small variation in aggregate labor supply. 
TABLE 5

Participation and Hours of Work: Scenarios nit50 $f$ and $p i 50 f$

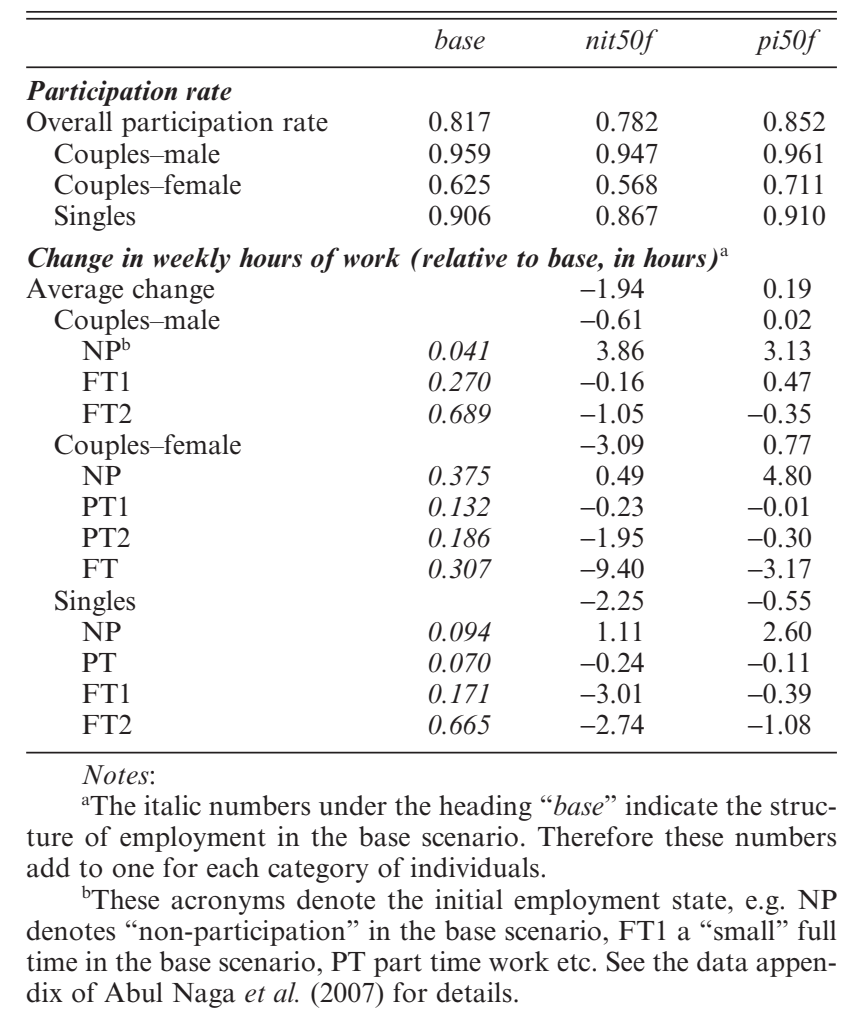

Additional insight can be obtained from the variation in participation rates and hours choices, as shown in Table 5. Two results stand out. First, the participation requirement has a powerful effect on the participation rate. If the benefit is paid unconditionally, as in scenario nit50f, some individuals tend to reduce their participation in the labor market. This effect is particularly pronounced for secondary earners in couples: female workers reduce their participation rates from 62.5 percent (base) to 56.8 percent (nit50f). The participation condition of scenario pi50 $f$ more than compensates for this disincentive to work: female workers increase their participation rate to over 70 percent. The conditionality of the benefit also prevents a fall in the participation rate of single-adult households.

Second, individuals who hold a full-time job in the base case tend to reduce their hours of work in the nit50f and pi50f scenarios. This effect, which is linked to the increase in the marginal tax rate, is again particulary strong for secondary earners. Women who worked full-time in the base scenario reduce on average their weekly amount of work by 3.2 hours under the pi50f scenario (see Table 5). The higher marginal tax rate in the nit $50 f$ scenario (51 percent compared to 42 percent in $p i 50 f$ ) leads to an even stronger reduction in weekly work hours of full-time female workers, by 9.4 hours on average. 
TABLE 6

Transitions In and Out of Poverty: Scenarios nit50f AND pi50f (POPULATION SHARES)

\begin{tabular}{lllll}
\hline \hline & \multicolumn{3}{c}{ Poverty line CSIAS $^{\mathrm{a}}$} \\
\hline \multirow{4}{*}{ base } & & \multicolumn{3}{c}{ nit50f } \\
& Poor & 0.003 & 0.031 & Total \\
& Not poor & 0.009 & 0.958 & 0.033 \\
& Total & 0.011 & 0.989 & 0.967 \\
& & & pisof & \\
base & Poor & Poor & Not poor & Total \\
& Not poor & 0.015 & 0.018 & 0.033 \\
& Total & 0.001 & 0.966 & 0.967 \\
& 0.017 & 0.983 & 1.000 \\
\hline
\end{tabular}

Note: ${ }^{a}$ The CSIAS poverty line is equal to CHF 23690.

To sum up, the increase in the participation rate compensates for the reduction in work hours of full-time workers in scenario pi50f. As a result, aggregate labor supply and average disposable income increase slightly despite the more progressive tax system. By contrast, the reduction in work hours in the nit50f scenario involves a feedback effect between labor supply and the balanced government budget: a reduction in labor supply yields a fall in income tax revenues, compelling the government to increase the flat tax rate. This, in turn, leads to a further reduction in labor supply. This adjustment process finally settles to a 6.4 percent drop in average disposable income.

Finally, it is interesting to analyze the role of the participation conditionality with respect to poverty. As discussed above, the pi50 $f$ reform does not reduce the poverty headcount to the level achieved by the nit50f scheme, primarily because those who do not participate in the labor market are not entitled to benefits under the former scheme. There is, however, another important difference between the two policies which becomes apparent by comparing the transitions in and out of poverty these two scenarios entail, starting from the base scenario. These transition frequencies are reported in Table 6. They show that, although the nit50f reform lifts a greater proportion of population out of poverty than pi50f, there is also a greater share of households whose disposable income now falls below the poverty line (almost 1 percent of the population at the CSIAS poverty line). Under the pi50f scenario, the participation requirement largely prevents this movement into poverty.

\section{Concluding Comments}

The purpose of this study was to examine the effects on the distribution of household disposable income of various income maintenance programs. Our benchmark scenario was the current situation in Switzerland, and the various schemes examined were a full NIT allowance, a partial NIT allowance, a participation income covering 50 percent of subsistence costs, an income support scheme which topped up household resources to the level of subsistence expenditure, and finally a (simplified) earned income tax credit. We were interested in capturing the 
effect of introducing such schemes on income inequality and poverty. However, we also wanted to examine the effect of the various income maintenance schemes on the overall level of social welfare. To address this last point, it was particularly important to model household labor supply responses to the alternative budget constraints entailed by the tax and benefit schedules of the various policy scenarios studied here.

By definition, the full NIT granting an allowance equal to subsistence needs was designed to eliminate poverty. The resulting scheme was shown to reduce income inequality most drastically. The ordinal analysis of income distributions also allowed us to establish that in comparison to the current situation in Switzerland, the bottom 65 percent group would unambiguously benefit from the introduction of a full NIT allowance. However, such an income maintenance scheme is expensive to fund: our results suggest that an integrated federal linear tax rate of 62 percent is required to make it viable. Under such taxation, aggregate work hours are reduced by 10 percent and average disposable income falls by 9.3 percent.

The partial NIT allowance is less generous in terms of social assistance, and is accordingly less effective than the full NIT allowance in reducing poverty and inequality. However, it also entails a smaller, though still significant, 5.9 percent sacrifice of total income for it to be viable. The participation income was designed to restrict the income allowance (50 percent of subsistence needs) to families with all adults in employment. Again, this last scheme was less effective than the full and partial NIT allowances in reducing poverty and inequality. However, of all the schemes examined in this paper, the participation income was the only scenario that resulted in an unambiguous social welfare improvement over the distribution of income pertaining to our benchmark scenario.

Finally, we discuss some limitations of our analysis, some of which may present directions for further research. Our family utility model abstracted from problems of rationing; i.e. unemployment, taking the state of not working as synonym to non-participation. Likewise, we have simplified our analysis by assuming non-existence of welfare stigma on the side of claimants. We have also ignored the administrative costs required to evaluate the situations of families with respect to the schemes that were designed to top up resources to the target subsistence level. In this respect, our results may have over-estimated the costs of operating variants of the negative income tax, and likewise may have underestimated the tax revenues required to top up resources in relation to our two means tested schemes.

Our analysis has omitted two major socio-economic groups: the selfemployed and individuals on retirement. It is not likely that schemes that provide incentives for participation such as the participation income and earned income tax credit will have much impact on the decision of the elderly to take up employment again. However, it is clear that occupational choices between salaried employment and self-employment may be very much influenced by the existing structure of social safety nets. One major extension of our analysis therefore could consist in modeling occupational choices and work decisions jointly using a sample of salaried and self-employed workers. Then, it is expected that this additional source of heterogeneity will result in larger reactions of households in terms of 
both income and changes in hours in the face of the alternative policy scenarios considered here.

Our microsimulation exercises were undertaken, as is most often the case, assuming that policy reforms did not impact on the demand for labor, so that hourly (pre-tax) wages could be held constant across scenarios. This is certainly one important limitation of this type of partial equilibrium modeling of policy reform. In the current state of science, general equilibrium modeling however implies a greater degree of aggregation of families into broad socio-economic categories. In this sense, partial equilibrium microsimulation exercises such as ours have the benefit of greater realism, at the cost of some simplifying assumptions.

\section{REFERENCES}

Aaberge, Rolf, Ugo Colombino, and Steinar Strom, "Do More Equal Slices Shrink the Cake? An Empirical Investigation of Tax-Transfer Reform Proposals in Italy," Journal of Population Economics, 17, 767-85, 2004.

Abul Naga, Ramses, Christophe Kolodziejczyk, and Tobias Müller, "The Redistributive Impact of Alternative Income Maintenance Schemes: A Microsimulation Study using Swiss Data," Cahiers du département d'économétrie 2007.03, University of Geneva, 2007. Available at: http:// www.unige.ch/ses/metri/cahiers/.

Atkinson, Anthony B., "On the Measurement of Inequality," Journal of Economic Theory, 2, 244-63, 1970.

- Public Economics in Action: The Basic IncomelFlat Tax Proposal, Clarendon Press, Oxford, 1995.

Blundell, Richard, "Welfare Reform for Low Income Workers," Oxford Economic Papers, 53, 189-214, 2001.

Blundell, Richard and Thomas MaCurdy, "Labour Supply: A Review of Alternative Approaches," in O. Ashenfelter and D. Card (eds), Handbook of Labor Economics, vol III, Elsevier, Amsterdam, 1999.

Bourguignon, François and Amedeo Spadaro, "Microsimulation as a Tool for Evaluating Redistribution Policies," Journal of Economic Inequality, 4, 77-106, 2006.

Creedy, John and Peter Dawkins, "Comparing Tax and Transfer Systems: How Might Incentive Effects Make a Difference?” Economic Record, 78, 97-108, 2002.

CSIAS (Conférence Suisse des Institutions d'Action Sociale), Aide Sociale, Concepts et Normes de Calcul, Paul Haupt, Bern, 2000.

Davidson, Russell and Jean-Yves Duclos, "Statistical Inference for the Measurement of the Incidence of Taxes and Transfers," Econometrica, 65, 1453-65, 1997.

Duclos, Jean-Yves, Abdelkrim Araar, and Carl Fortin, "DAD, A Software for Distributive Analysis/ Analyse Distributive," MIMAP program, International Development Research Centre, Government of Canada and Créfa, Université Laval, 2005.

Duncan, Alan and Christopher Giles, "Labour Supply Incentives and Recent Family Credit Reforms," Economic Journal, 106, 142-55, 1996.

_-, "The Labour Market Impact of the Working Families Tax Credit in the UK," mimeo, Institute for Fiscal Studies, 1998.

Foster, James, Joel Greer, and Erik Thorbecke, "A Class of Decomposable Poverty Measures," Econometrica, 52, 761-6, 1984.

Fredriksen, Dennis and Nils Martin Stølen, "Effects of Demographic Developments, Labour Supply and Pension Reforms on the Future Pension Burden in Norway," in A. Harding and A. Gupta (eds), Modelling Our Future: Population Ageing, Social Security and Taxation, International Symposia in Economic Theory and Econometrics, North Holland, Amsterdam, 2007.

Friedman, Milton, Capitalism and Freedom, Basic Books, New York, 1962.

Gerfin, Michael and Robert E. Leu, "The Impact of In-Work Benefits on Poverty and Household Labour Supply: A Simulation Study for Switzerland," discussion paper 03-04, University of Bern, 2003.

Goodin, Robert E., "Erring on the Side of Kindness in Social Welfare Policy," Policy Sciences, 18, $141-56,1985$. 
Kornstad, Tom and Thor O. Thoresen, "Effects of Family Policy Reforms in Norway: Results from a Joint Labour Supply and Childcare Choice Microsimulation Analysis," Fiscal Studies, 27, 339-71, 2006.

Leu, Robert E., Stefan Burri, and Tom Priester, Lebensqualität und Armut in der Schweiz, Paul Haupt, Bern, 1997.

Merz, Joachim, "Market and Non-Market Labour Supply and the Impact of the Recent German Tax Reform-Incorporating Behavioural Response," in A. Harding (ed.), Microsimulation and Public Policy, Contributions to Economic Analysis Series, North Holland, Amsterdam, 1996.

Moffitt, Robert, "An Economic Model of Welfare Stigma," American Economic Review, 73, 1023-35, 1983.

, "The Negative Income Tax and the Evolution of US Welfare Policy," National Bureau of Economic Research WP 9751, 2003.

Orsini, Kristian, "Tax-Benefits Reforms and the Labor Market: Evidence from Belgium and Other EU Countries," mimeo, 2006.

Shorrocks, Anthony F., "Ranking Income Distributions," Economica, 50, 3-17, 1983.

Sen, Amartya, "The Political Economy of Targeting," in Dominique Van de Walle and Kimberly Nead (eds), Public Spending and the Poor: Theory and Evidence, Johns Hopkins University Press, Baltimore, 1995.

Steiner, Viktor and Katharina Wrolich, "Introducing Family Tax Splitting in Germany: How Would it Affect the Income Distribution and Work Incentives?" IZA discussion paper 2245, 2006.

van Soest, Arthur, "Structurals Models of Family Labor Supply: A Discrete Choice Approach," Journal of Human Resources, 30, 63-88, 1995. 